\title{
Los libros de lectura y i"una"? Argentina para los niños de mediados del siglo XX. Entre El Alma Tutelar y la Ruta Gloriosa
}

\section{Textbooks and "Only One"? Argentina for Children in the mid-20th Century. Between the Tutelary Soul and the Glorious Route}

\author{
NOEMÍ GIRBAL-BLACHA
}

\begin{abstract}
Resumen
Este estudio histórico aborda la relación entre poder y cultura vinculada a la educación de nivel primario durante la década de 1950, en la Argentina que cuestiona el sistema republicano. La enseñanza dirigida a los niños es importante. Los libros de lectura utilizados en este primer ciclo escolar, resultan instrumentos de alfabetización y formación de la identidad nacional y ciudadana. Aproximarse a esas herramientas educativas mediante dos estudios de caso: El Alma Tutelar y Ruta Gloriosa, orienta el análisis crítico de estas fuentes primarias, para describir e interpretar la influencia ejercida sobre estos alumnos en tiempos políticos diversos y conflictivos.
\end{abstract}

Palabras clave

Niñez; Lectura; Peronismo; Antiperonismo.

\begin{abstract}
This historical research addresses the relationship between power and culture linked to primary level education during the 1950s, in an Argentina questioning the Republican system. Education aimed at children was important. The textbooks used in this first school stage are instruments of literacy and formation of national identity and citizenship. Approaching these educational tools through two case studies, El Alma Tutelar and Ruta Gloriosa, guides the critical analysis of these primary sources, in order to describe and interpret the influence exerted on these students in diverse and conflictive political times.
\end{abstract}

Keywords

Childhood; Reading; Peronism; Anti-Peronism.

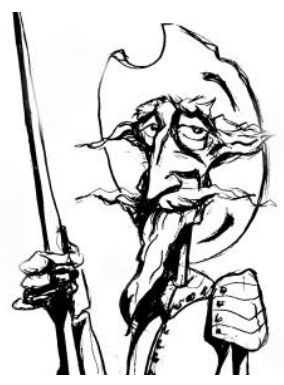

Recibido con pedido de publicación el 6 de mayo de 2021

Aceptado para su publicación el 13 de julio de 2021

Versión definitiva recibida el 12 de septiembre de 2021

https://doi.org/10.35305/prohistoria.vi36.1525

Noemí Girbal-Blacha, Consejo Nacional de Investigaciones Científicas y Técnicas, Universidad Nacional de Quilmes, Quilmes, Argentina; e-mail: noemigirbal@gmail.com 
“Los libros transforman a la sociedad, sí. Las obras de masiva difusión pueden modificar y plasmar las experiencias y las representaciones del hombre."

Roger Chartier ${ }^{1}$

\section{Planteo del tema}

Este estudio histórico se propone abordar la relación entre poder y cultura con referencia a la educación de nivel primario durante la década de 1950, en tiempos del liderazgo de Juan Perón y cuando se produce su derrocamiento e impone sus reglas la llamada "Revolución Libertadora", desde el 16 de setiembre de 1955. En un país como la Argentina que padece reiterados golpes de Estado que cuestionan la democracia, las instituciones y el sistema republicano, la educación -como red de contención que permite superar culturalmente esos quiebres políticos- juega un papel importante, especialmente la dirigida a los niños. Se trata de un tema que ha recibido la atención desde diversos enfoques historiográficos (Tedesco, 1980, 1986 y 2020; Puiggrós, 1996 y 2003; Filmus, 1996; Braslavsky, 2005; Somoza Rodríguez, 2006; Sardi, 2009; Ascolani, 2010 y 2019:149-162, entre otros).

Los libros de lectura utilizados en la escuela pública durante el primer ciclo de escolaridad resultan instrumentos básicos de alfabetización y formación a la hora de caracterizar y conformar la identidad nacional, las instituciones, ponderar las diferencias regionales, la diversidad de los actores sociales y la formación ciudadana (Filmus, 1996; Braslavsky, 2005). A partir de las estructuras argumentativas de la historia -que también registran estos textos- se pone énfasis en la construcción discursiva destinada a penetrar y moldear la memoria colectiva. Aproximarse a esas herramientas de formación a través de dos estudios de caso: los libros de lectura El Alma Tutelar y Ruta Gloriosa (primer grado superior y cuarto grado de la enseñanza primaria, respectivamente) es el desafío que orienta el análisis crítico de estas fuentes primarias para describir e interpretar la influencia que ejercieron en los niños de esa generación de mediados del siglo $X X$, en tanto alumnos de la escuela pública en contextos políticos diversos y conflictivos. El propósito es sumar esta interpretación a la calificada historiografía que aborda la historia de la educación argentina.

La educación ha sido uno de los pilares que permitieron conformar la Argentina Moderna, la de la Generación del 80, agroexportadora, país de

\footnotetext{
1 Entrevista a Roger Chartier, junio de 2015. [en línea] http://noticias.unsam.edu.ar/2015/06/12/entrevista-a-roger-chartier-la-sociedad-transforma-loslibros/
} 
inmigración y con urbanización creciente, cuando en 1880 se crea el Estado Nacional como aparato institucional y relación social. Entonces la educación deja de estar vinculada a la Iglesia para ser una competencia estatal, pública, laica, gratuita y obligatoria hasta los 14 años de edad (Zanatta y Di Stefano, 2009). La formulación de sus planes y programas de estudio quedan supeditados -como el registro y el matrimonio civil- a la gestión del Estado, liderado por una elite de conservadores en lo político y liberales en materia económica. Desde la sanción de la ley 1.420 en 1884, la educación pública sería un sólido instrumento para ejercer el poder y moldear la identidad de la sociedad y la Nación. El papel de la educación en la construcción de la hegemonía, entendida como un cuerpo de prácticas culturales que pretende transformar intereses sectoriales en generales como parte del dominio del Estado, muestra así sus dos funciones (Zubieta, 2000: 37-41). Para los sectores dirigentes se presenta como un vehículo de "orden social". Para los inmigrantes, sus hijos, los sectores trabajadores y la clase media, en cambio, la educación es sinónimo de ascenso social (Puiggrós, 2003: 24).

Poder, cultura y educación componen una ecuación compleja que incide en el comportamiento social y no es ajena a los vaivenes políticos. El poder es algo más que una expresión jurídica, "representa una relación desigual de fuerzas" móviles y con registros de coherencias y contradicciones. Expresa las hegemonías sociales y genera resistencia. En un espacio público político como el de la cultura y específicamente de la educación, el poder pretende legitimarse como una expresión de las estructuras de comunicación, más allá de la diversidad en las formas de definirlo. Si para Max Weber representa la posibilidad de imponer en cada caso la propia voluntad ante el comportamiento de los otros; para Hannah Arendt el poder es un modelo comunicativo de acción y apegado al pensamiento aristotélico, presentándose como la capacidad para desplegar una acción en común. En cualquier caso, las instituciones políticas son manifestaciones del poder en acción, pero para Arendt y otros teóricos del poder, la praxis es el rasgo fundamental de la reproducción cultural de la vida (Habermas, 1986: 200-210).

Michel Foucault, por su parte, se refiere a la "polivalencia táctica de los discursos" (Foucault, 1985). Poder y saber se articulan en el discurso, que a su vez se refleja en la educación y en los valores transmitidos u omitidos como parte de un mensaje que acepta o excluye. Se trata de una multiplicidad de elementos argumentativos que actúan de modo distinto ante estrategias diferentes. "El discurso transporta y produce poder", afirma Foucault, al mismo tiempo que le marca límites y le propone tolerancias (Terán, 1985). La cultura y la educación están nutridas de ese discurso y suele expresarse en los libros (Campbell, 1997: 2732). Los textos cambian con el tiempo y también se modifica su materialización. Ambos aspectos deben ser identificados para entender cómo se construyen en cada 
momento histórico. Son los lectores, dice Roger Chartier, quienes se apropian de los efectos de sentido a los que se dirigen "los libros, los usos y los significados impuestos por las formas de publicación y circulación, y las competencias y las exigencias que rigen la relación que cada comunidad mantiene con la cultura escrita" (Chartier, 2007: 63).

El discurso que compone la lectura acompaña los hechos, a los cuales legitima o descalifica, en tanto conjunto de procedimientos intelectuales y forma de comunicación (Habermas, 1973: 9-11). Por su parte, la historia es la que articula y distingue diferentes tiempos. Para R. Chartier, las temporalidades "no deben ser consideradas como envolturas objetivas de los hechos reales", sino como el producto de construcciones sociales diversas y desiguales (Chartier, 2007: 93). Y en este sentido, el análisis discursivo de los textos, así como su estilo retórico, aportan algunas claves para comprender políticas diversas de gobierno, el uso político del pasado y en tanto expresión de la cultura escrita. Ocurre en los tiempos en que el carismático Juan Domingo Perón lidera la Argentina de mediados del siglo XX, cuando enlaza la legitimidad de su poder con la participación popular, que va más allá del ejercicio regular del sufragio (De Ipola, 1999: 325-332; Lechner, 1997: 33-35). También se manifiesta cuando mediante un golpe de Estado, en 1955, se busca desconocer e invisibilizar el pretérito inmediato, mediante un uso político sesgado del pasado, hasta modificar la estética, la liturgia y los principios de los tiempos precedentes (Álvarez Junco, 1994: 11-38). En ambos casos quienes conducen el proceso gubernamental concentran una excepcional capacidad organizadora y manipuladora que sostienen, con argumentos encontrados pero efectivos, la división de la sociedad en dos campos antagónicos: peronistas vs antiperonistas.

Si a mediados del siglo XX el discurso plasmado en la lectura especialmente en los manuales y libros para los niños que cursan sus estudios primarios- sirve para consolidar el culto al líder, sus realizaciones y la difusión de la doctrina nacional que arraiga mitos y fidelidades en la sociedad argentina de los tiempos del peronismo, no es menos cierto que en las etapas de gobiernos intervencionistas de los años de 1930 y desde 1955 con el ejército y el nacionalismo católico en el poder, las consignas de la lectura para estos mismos niños, plasmarían otra concepción de la identidad y de la Nación Argentina, no exentas de contradicciones, pero también de permanencias, que se abordan aquí con especificidad a través de los estudios de caso propuestos, para dar consistencia y singularidad a los objetivos de este trabajo. 


\section{Política y educación pública infantil a través de los libros de lectura. Aproximaciones}

El libro de lectura es un instrumento importante para la organización de los contenidos didácticos propios de la educación básica. El texto contiene además de las lecciones, los ejercicios vinculados a la lectura y la comprensión del texto, el esparcimiento asociado a los valores y al territorio, así como el vocabulario correspondiente que debe ser definido para el lector $\mathrm{y}$, en algunos casos, la ejercitación que el alumno debe hacer de esos conceptos. Estos libros suelen estar organizados por temas que responden a los contenidos curriculares del grado correspondiente a la enseñanza impartida en la escuela pública argentina y que impulsa históricamente el discurso hegemónico acerca de la Nación (Sardi, 2009: 151; Ascolani, 2010: 303-325).

Si la construcción de la Nación es la idea fuerza del siglo XIX, el normalismo argentino influido por el higienismo en el contexto del positivismo de las últimas décadas de esa centuria, encuentra en la educación un instrumento central para moldear valores morales, de comportamiento, jerárquicos y de orden, como parte de "un apostolado" docente que otorga poder a través del saber y se nutre de la cultura imperante en el otro lado del Atlántico y, generalmente, de espaldas al pasado originario de la Argentina. La llegada de la democracia al gobierno en 1916, de la mano del partido radical liderado por Hipólito Yrigoyen, se mostraría proclive a lograr algunos cambios, capaces de impulsar la integración de los inmigrantes, abierto a experiencias pedagógicas europeas y a una mayor inclusión social en todos los niveles de la enseñanza. Por estas razones consideraría a "la educación moral como el medio más idóneo para producir una 'revolución pacífica' y al sistema educativo escolarizado como el instrumento adecuado para realizarla" (Puiggrós, 2003: 26). El radicalismo hace una interpretación de la ley 1.420 de educación común (1884) que rescata los aspectos promotores de la intervención social a través de los consejos escolares y de las bibliotecas populares, por ejemplo (Tedesco, 1986).

Comienza a gestarse "la escuela activa" (Puiggrós, 2003: 27), cuando cobra importancia en la educación del país "el pragmatismo democrático del pedagogo norteamericano John Dewey", en tanto sistema integral que concilia educación con trabajo a través de laboratorios y talleres; dando "prioridad a las necesidades biológicas y psicológicas del niño y basada en los principios de la Ley 1420" (Puiggrós, 2003: 31). De todos modos, son los Manuales -para la enseñanza de la lengua, las matemáticas y de las ciencias sociales y naturales- los que presentan una Argentina de regiones diversas. Los libros de lectura, en cambio, muestran el mundo ideal capitalino, preferentemente urbano que pretende reflejarse en el espejo europeo, asentado en los valores del trabajo y la educación, mientras 
incluyen algunas referencias a la Argentina agroexportadora, al puerto y -en todos los casos- a los monumentos y símbolos patrios, como fundamentos de la identidad nacional.

El Estado interventor surgido en los años de 1930 para subsidiar a la Argentina agroexportadora asediada por el fin del crecimiento hacia afuera, crea las Juntas Reguladoras de la producción a partir de 1932, auspicia la industrialización sustitutiva de importaciones como una opción complementaria y modifica el sistema financiero en 1935 mediante la creación del Banco Central de la República Argentina y el Instituto Movilizador de Inversiones Bancarias, con el propósito de evitar el impacto directo de las crisis internacionales en una economía abierta como la argentina. En un contexto de desocupación creciente impulsado por el crac neoyorkino de 1929, la educación se constituye -más que en otros períodos- en un instrumento de "control social" y da cuenta del país y la sociedad de entonces a través, por ejemplo, de la literatura realista y de los libros de lectura. La propuesta no es nueva en sus raíces, pero se acentúa el disciplinamiento social como parte del intervencionismo estatal, del nacionalismo doctrinario de elite (Barbero y Devoto, 1983: 36-47; Tedesco, 1980), de la ruptura del consenso ideológico y el "fin de las certezas" (Cucuzza, 2007).

A mediados del decenio de 1930 el libro de lectura para tercer grado de la Profesora de gramática histórica Clara Toro y Gómez titulado La Escuela y la Vida (Editorial Kapelusz, 1935) muestra en su tapa -como otros similares de esa épocalas imágenes de la Argentina agraria y de la industrialización sustitutiva de importaciones, como telón de fondo en el cual se recorta la silueta de un niño de clase media, pensativo y prolijo. El texto incluye un índice metódico que sintetiza las bases de la educación de valores para la infancia argentina y responde a los programas oficiales del Consejo Nacional de Educación:

1. La familia-El hogar (11 lecturas);

2. La patria (13);

3. La conducta-Defectos y cualidades (27);

4. La naturaleza (14);

5. El trabajo-La escuela (16).

Cada lectura tiene un glosario y preguntas acerca del tema de las mismas. Es la propia autora quien expone el objetivo de este libro "para que el alumno observe su propia conducta y la organice conscientemente". También reconoce como propósito "facilitar la tarea del maestro", quien deberá lograr que la lectura resulte provechosa para el niño porque debe "formar parte de su vida moral e intelectual", así como "acostumbrar al niño a la reflexión" (Toro y Gómez, 1935: 5). 
Varias de sus lecturas -con dibujos sencillos en color sepia- pertenecen a autores reconocidos e intelectuales vinculados al pasado fundacional de la Nación Argentina como Mariano Moreno, Esteban Echeverría, Domingo F. Sarmiento, Bartolomé Mitre, Juan María Gutiérrez, Marcos Sastre, Tomás de Iriarte, Juan Meléndez Valdéz, Carlos Octavio Bunge, Enrique Rivarola, Santiago Estrada, Calixto Oyuela, entre otros. Sólo figura una lectura de autoría femenina, la de la actriz dramática Sarah Bernhardt, titulada "Carta de una madre a su hijo", donde esa madre reprocha en duros términos el poco apego por la educación que manifiesta su hijo, mientras expresa su temor a la pobreza, la vejez y la soledad. Educar por medio de "la culpa" es el mensaje que transmiten varias de estas lecturas cuya protagonista principal es la madre, más que el padre, por su responsabilidad de entonces en la crianza de los hijos. El valor de la familia, de la buena conducta, del trabajo digno y del amor a la patria se destacan como ejes de esta educación inicial (Sardi, 2009: 152-154; Ascolani, 2020: 1-23). Este libro -que, como otros de la época, tiene largos textos con pocas y descoloridas ilustracionesresulta también aprobado por varios Consejos de Educación provinciales, pero son escasas las referencias regionales y las de sus costumbres -más allá de la región cerealera- invisibilizando las economías agroindustriales y la explotación forestal, yerbatera, tabacalera, con sus singularidades sociales y económicas.

\section{Imagen 1}

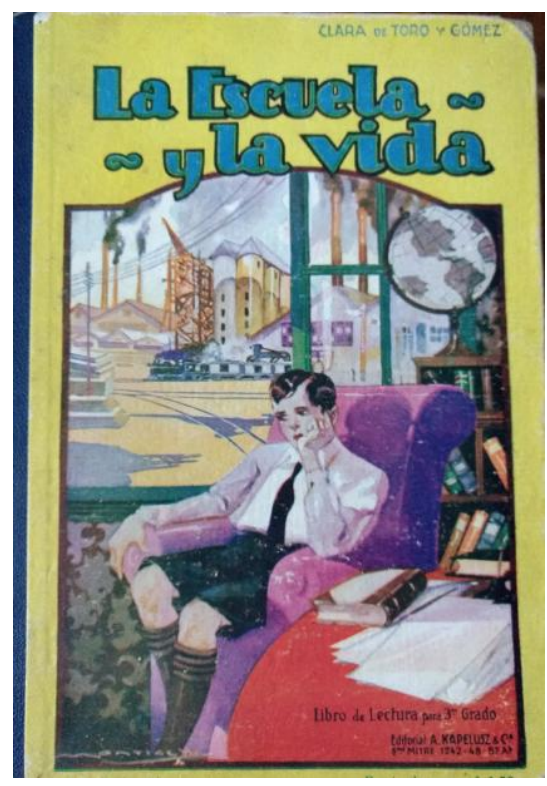

Toro y Gómez, C. (1935). La Escuela y la Vida.

Libro de lectura para 3er grado. Editorial Kapelusz. 
Más allá de los efectos de la primera ruptura del orden institucional en la Argentina de los años 30, los conceptos y valores a transmitir mediante la educación pública se mantienen inalterables, comparados con los de fines del siglo XIX. La dedicación materna, el esfuerzo paterno, la unión en la familia, las tareas domésticas y la conducta durante "las visitas" como parte de la formación de las niñas, así como la educación y el trabajo representados en tanto mecanismos para el ascenso social, el valor ético del ejemplo, el comportamiento para con los demás traducido en "las consecuencias de nuestros actos" (Toro y Gómez, 1935: 82-83 y 42-44), la caridad, "la modestia”, "la cortesía", "la aplicación”, las consecuencias de ser una "niña desordenada" o un "niño desobediente", el respeto a los mayores, a los animales y a la naturaleza, así como los símbolos y las fechas patrias asociadas a los hombres del pasado fundacional de la Nación, siguen formando parte de la educación básica y de los "consejos para los niños", en una Argentina identificada con "el granero del mundo" (Toro y Gómez, 1935: 91-93, 132-134, 71 y 54).

Los cambios ocurridos en la sociedad y la política argentinas desde los años 1940 seguirán manteniendo estos pilares de la educación pública, con un mensaje político más explícito, con mayor culto a la personalidad, destacando la importancia del mercado interno, del trabajo y de los trabajadores reconocidos como protagonistas por el derecho impulsado desde un Estado dirigista, popular y nacionalista a partir de mediados de ese decenio (Somoza Rodríguez, 2006). Pero también se propiciará el mensaje político cuando a medidos de la década de 1950 vuelva a interrumpirse el orden institucional en el país y si bien se ignora el pretérito político inmediato de la Nación, ya no habrá vuelta atrás en las bases sociales mencionadas y que se registran a través de la educación. El mensaje apelará a otros términos menos personalistas para respaldarse en el pasado fundacional de la Argentina. Las bases de la formación educativa de la infancia conforman un entramado capaz de trascender esos quiebres de la democracia y el eclipse de sus instituciones. El abordaje del decenio 1950-1960 a través de los libros de lectura, analizados microhistóricamente y como estudios de caso en cada etapa, es el desafío de las páginas siguientes, para poder comprender las permanencias y los cambios en la enseñanza primaria, más allá de las fracturas políticoinstitucionales.

\section{Un modelo dicotómico de país para la infancia de mediados del siglo XX}

En tiempos de la segunda posguerra, el dirigismo estatal encarnado en un gobierno nacional popular, nacionalista y planificador liderado por el "Coronel de los Trabajadores" Juan Domingo Perón, desde el 4 de junio de 1946, el mercado 
interno se fortalece al amparo de la redistribución del ingreso y como respuesta a la doctrinaria "justicia social, soberanía política e independencia económica". El discurso de confrontación basado en el principio de "pueblo vs. oligarquía", seduce a unos y motiva la reacción de quienes son descalificados por su condición de opositores. Un vínculo místico une al líder con el "pueblo trabajador" y sus atributos personales son asimilados a "íconos de sus culturas", a través de un proceso de construcción mitológica. El peronismo presenta rasgos de heterogeneidad y complejidad mayores de los que su imagen monolítica aparenta, especialmente cuando desde 1950 la sociedad argentina se divide -promovida desde el Estado- en "peronistas vs. antiperonistas" (De la Torre, 1994: 39-60; Girbal-Blacha, 1997: 63-77; Prost, 1996: 127-140; Rioux et Sirinelli, 1997: 7-20). Interpretar el peronismo es un desafío que comprende dicotómicamente, peronización y desperonización de la sociedad, a partir de 1955, con toda su carga simbólica (Sidicaro, 1995: 31-38).

"Mitos y paradojas" (Bairoch, 1995) se expresan en el discurso oficial, en los medios gráficos y en la iconografía propia de los gobiernos populares, entre mediados de los años de 1940 y hasta 1955, y deben analizarse en el contexto de crisis del discurso liberal de entonces. Es cuando Juan Perón se apropia de una serie de críticas al liberalismo, transformándolas en discurso de confrontación que identifica con los rasgos distintivos de la "Nueva Argentina" para oponerlos a los típicos de la "Argentina oligárquica". El gobierno nacional y popular se muestra preocupado por la reformulación de la identidad nacional "asimilada a una tradición que se creía enterrada y que vuelve a la superficie" (QuattrocchiWoisson, 1995: 233). Historia y política labran una alianza que no es nueva, pero que como otras expresiones populistas latinoamericanas utiliza con frecuencia la propaganda oficial registrada a través de los medios de comunicación (escritos, radiales y cinematográficos). Se forja un estilo más explícito y doctrinario del vínculo entre cultura, educación y poder político.

En medio de esta coyuntura, el 29 de setiembre de 1947 la ley 13.049 autoriza al Poder Ejecutivo a convenir con el Banco Central la inversión de hasta m\$n 25.000.000 en "un fondo especial para créditos extraordinarios de ayuda y fomento a las editoriales argentinas que impriman en el país, constituidas como tales al $1^{\circ}$ de enero de 1946 con prescindencia absoluta de cualquier otro préstamo común o bancario y en las sumas que soliciten, hasta el $50 \%$ de su capital" (art. 19). Se trata de préstamos a 5 años con el $5 \%$ de interés anual (cuando la tasa ordinaria es del $7 \%$ ) y factibles de ser ampliados a medida se amortizan, con previo asesoramiento de la Sociedad Argentina de Editores. ${ }^{2}$ La disposición se respalda en

${ }^{2}$ Leyes y Decretos Nacionales (LyDN) 1947, Buenos Aires, 1948, vol. 2, pp. 12-13 
otra similar del Banco de la Nación Argentina, que en agosto de ese año dispone "un préstamo especial de ayuda a las empresas editoras cuya producción represente un aporte valorable cultural y científicamente" (BNA, 1948: 32) que incluye permisos para importar papel. Mientras el Banco de Crédito Industrial desde 1948, ofrece su crédito "a las editoriales que impriman sus obras en talleres propios". ${ }^{3}$ Los préstamos más ventajosos alcanzan a pocas editoriales -como Jacobo Peuser, Kraft SRL, Luis Laserre, Codex SRL, Tor SRL- que editan publicaciones oficiales y libros de lectura para la enseñanza primaria. Se desvirtúa la consigna opositora "alpargatas si, libros no" y oficialmente se trata de afianzar la doctrina en las bases populares mediante la educación y la cultura con sentido práctico e inclusivo (Girbal-Blacha, 2012: 110-134).

La industria de la edición crece sostenidamente desde los años de 1930, pero alcanza con el peronismo un mayor impulso. Entre 1900-1935 se publican en la Argentina 2.359 obras. Entre 1936 y 1939 la cifra asciende a 5.536. Entre 1941 y 1945 los ejemplares editados en el país alcanzan a 123.700 .000 y entre 1946-50 a 145.800.000 ejemplares (siendo exportados un 40\% de ese total). Las empresas de edición son 69 en 1943, un año después totalizan 156 y, con altibajos, van en aumento durante la década peronista. Algunas editoriales están en manos de opositores y son miembros prominentes del CLES (Colegio Libre de Estudios Superiores) (Belini, 2018: 264-293). Ocurre con Losada, Sur, Emecé, Claridad, Sudamericana, Raigal, Siglo XX, Paidós, El Ateneo, Hachette y otras, que no están alcanzadas por los beneficios del crédito oficial (Bottaro, 1964; García, 1965; Rivera, 1998).

En 1948 la doctrina que sintetiza el Manual del Peronista, expone (capítulo XIII) su concepción acerca de la cultura como "preparación moral y arma de combate" y de la educación, en manos de "los maestros que plasman y modelan diariamente en las escuelas a los hombres del mañana, de quienes depende la grandeza de la nacionalidad". La propuesta es que la educación tenga "una orientación un poco más argentina", menos enciclopedista, afirma el manual (Partido Peronista, 1988: 31). Trabajo y educación se convierten en los instrumentos centrales para el ascenso social, cuando, por ejemplo, el decreto 8.954 crea 25 escuelas monotécnicas. ${ }^{4}$ Se trata, al mismo tiempo, de un desafío dirigido a los intelectuales cuando la dimensión simbólica del poder propone legitimar la inclusión social mediante un discurso que da consistencia a esas premisas como impulsoras de una nueva categoría social: "el intelectual nacional y popular" que reúne a figuras disímiles del propio espectro peronista, como las de Arturo

\footnotetext{
${ }^{3}$ LyDN, 1948, Buenos Aires, 1949, vol. 1, pp. 275-276.

${ }^{4}$ Secretaría de Educación (1948). Decreto 8.954, Buenos Aires, 27 de marzo (Folleto).
} 
Jauretche y Juan José Hernández Arregui (Neiburg, 1998: 60-61; Altamirano, 1999: 314-324).

La Constitución Nacional reformada en 1949, en su artículo 37 (parte IV), uno de los más innovadores en materia social y cultural, se refiere a "la educación y la cultura". Respecto del tema que nos ocupa, declara que "la enseñanza primaria elemental es obligatoria y será gratuita en las escuelas del Estado", mientras dispone que la enseñanza primaria en las escuelas rurales "tenderá a inculcar en el niño el amor a la vida del campo, a orientarlo hacia la capacitación profesional en las faenas rurales y a formar la mujer para las tareas domésticas campesinas. El Estado creará, con ese fin, los institutos necesarios para preparar un magisterio especializado" (Sampay, 1975: 508). Gratuidad y obligatoriedad que se mantienen desde la década de 1880 (ley 1.420) para niños y niñas de hasta 14 años y que en lo referente a la escolaridad rural no difiere en esencia de la normativa vigente, que en los libros de lectura para el ciclo primario sólo se refleja en muy pocas de ellas, cuando atienden a las economías regionales agroindustriales, mientras la mayoría de sus páginas están dirigidas a ponderar el "granero del mundo", la urbanización, el puerto y el trabajador asociado a la industria que produce para el mercado interno. La propuesta es que el estudiante - en cada nivel educativo- conozca "la esencia de lo argentino, la realidad espiritual, económica, social y política de su país" así como "la evolución y misión histórica de la República Argentina" (Sampay, 1975: 540-541). La importancia de la función del Estado en la creación de escuelas, universidades y academias se explicita como expresión del nacionalismo popular y de su llegada a los sectores populares, pero también en relación con sus propias prioridades, referidas a la afirmación de la identidad, la adhesión a la "doctrina nacional" y la conformación de la "comunidad organizada".

Desde 1950 el Estado refuerza el control sobre la sociedad civil. Los asilados políticos deben ajustarse al decreto 19.935 de 1949 o la gendarmería nacional estaría habilitada para intervenir. Al mismo tiempo, el decreto 17.906 del 28 de agosto, pretende "fortalecer el régimen representativo republicano" y dispone que los empleados o funcionarios públicos puedan "afiliarse a alguno de los partidos políticos legalmente reconocidos", derogándose el decreto 32.577 de 1945 que lo prohibía expresamente. Son acciones que refuerza la ley 13.985 promulgada el 11 de octubre de 1950, al señalar que el Estado argentino "busca asegurar la defensa de los sagrados intereses nacionales sujetos, en la época presente principalmente, a posibles ataques ocultos de agentes y agrupaciones que respondiendo a intereses opuestos a los de la Nación pretendieran debilitar su potencial integral"; el sabotaje, el espionaje y la traición a la Nación son penalizados y hasta se contempla la reclusión perpetua o la aplicación de la pena de muerte (art. 11, ley 13.985) para 
quienes participen de estas actividades consideradas disolventes. ${ }^{5} \mathrm{El}$ catolicismo y la hispanidad estructuran "la argentinidad" y la educación se respalda en esos valores institucionales impulsados por el Estado.

En este contexto y de modo sostenido se fortalece el culto a María Eva Duarte de Perón, "Evita", que se expresa no sólo en la propaganda oficial sino también en los libros de lectura y materiales educativos, más coloridos e ilustrados que los de los decenios anteriores. El 7 de mayo de 1952 el Congreso Nacional luego de otorgar a Juan Perón el título de "Libertador de la República", designa "Jefa Espiritual de la Nación" a su esposa. ${ }^{6}$ La ley 14.126, de julio de ese año, determina que los planes de estudio de todos los establecimientos de enseñanza primaria, secundaria, normal, técnica, superior y en las escuelas de orientación profesional incluyan la lectura y comentario de la obra La Razón de mi Vida (atribuida a Eva Perón), disponiéndose su distribución gratuita y el otorgamiento de becas "para la mejor glosa o composición sobre el contenido popular del libro y sobre su ilustre autora" (art. 7). La ley 14.128, por su parte, otorga a Eva Perón "el derecho al uso del Collar de la Orden del Libertador San Martín" héroe máximo de los argentinos, con carácter vitalicio, "en mérito a los excepcionales servicios prestados por ella al Pueblo de la Patria, el espíritu de sacrificio y las virtudes de la más pura tradición sanmartiniana". ${ }^{7}$ Los niños que cursan la escolaridad primaria también reciben estos mensajes a través de sus libros de lectura.

Desde 1953 el Segundo Plan Quinquenal conceptualiza la Doctrina Nacional como "una nueva filosofía de la vida". En materia de educación el objetivo fundamental es "realizar la formación moral, intelectual y física del Pueblo" sobre la base de los principios de la Doctrina Nacional Peronista. La "cultura nacional" tiene que adecuarse a sus principios, pues "debe ser como la misma doctrina: simple, práctica, popular, cristiana y humanista" (Presidencia de la Nación Argentina, 1955: 283; 1953: 77-94). Se trata de adaptar y distribuir mejor los principios existentes como parte de la política cultural oficialista, mediante la asistencia técnica y económica, jerarquizando la cultura popular y procurando difundir el libro argentino. La redacción de un "Diccionario Nacional" que registre nuestra lengua, es sólo una de las numerosas propuestas estatales que procura reforzar "el tradicionalismo cultural" al que adhiere el gobierno peronista (Ciria, 1983: 215). ${ }^{8}$

\footnotetext{
${ }^{5}$ LyDN 1950, Buenos Aires, 1950, vol. 1, pp. 138-141; 265-266 y 464-465; 1952, Buenos Aires, 1953, col. 2, pp. 386-392.

${ }^{6}$ LyDN 1954, Buenos Aires, 1954, vol. 1, p. 495 (decreto 8480 del 20/5/54).

${ }^{7}$ LyDN 1952, Buenos Aires, 1953, vol. 2, pp. 3-7.

8 Argentina en marcha publicada por la Comisión Nacional de Cooperación Intelectual en 1947, es un ejemplo explícito de esta propuesta.
} 
Cuando el 16 de setiembre de 1955 se produce el derrocamiento del Presidente Juan D. Perón por parte de las fuerzas armadas, que encabezan la autodenominada "Revolución Libertadora", el lema "ni vencedores ni vencidos" que enarbola el nacionalismo católico cordobés representado por el General Eduardo Lonardi habría de mostrar, en un par de meses, la debilidad de ese propósito de unidad nacional. Una vez más la Argentina asiste a la interrupción del orden institucional, en esta ocasión mediante la fuerza inusual de la armada representada por el Altte. Isaac Rojas quien presidiría desde octubre una Junta Consultiva del Ejecutivo, como máxima expresión del antiperonismo y acompañado desde noviembre de ese mismo año por el General Pedro Eugenio Aramburu, como Presidente de facto de la Nación. Invisibilizar el accionar y las expresiones del peronismo que cuenta con arraigo en, al menos, la mitad de la población del país a pesar de la destitución del "Líder de los Trabajadores" es el propósito esencial de quienes ocupan desde entonces el poder, y la educación como la cultura en general- es uno de los vehículos principales para concretar ese objetivo.

El decreto-ley 4.161 del 5 de marzo de 1956 y en consonancia con el decreto 3.855/55 (6) "por el cual se disuelve el Partido Peronista en sus dos ramas en virtud de su desempeño y su vocación liberticida", expone literalmente los alcances de las medidas adoptadas por los hombres que lideran el gobierno de facto. En su artículo $1^{\circ}$ se prohíbe en todo el territorio de la Nación Argentina:

“...la utilización, con fines de afirmación ideológica peronista, efectuada públicamente, o propaganda peronista, por cualquier persona, ya se trate de individuos aislados o grupos de individuos, asociaciones, sindicatos, partidos políticos, sociedades, personas jurídicas públicas o privadas de las imágenes, símbolos, signos, expresiones significativas, doctrinas artículos y obras artísticas, que pretendan tal carácter o pudieran ser tenidas por alguien como tales pertenecientes o empleados por los individuos representativos u organismos del peronismo".

Considerándose violatoria de esta disposición "la utilización de la fotografía retrato o escultura de los funcionarios peronistas o sus parientes, el escudo y la bandera peronista, el nombre propio del presidente depuesto el de sus parientes, las expresiones "peronismo", "peronista", "justicialismo", "justicialista", "tercera posición", la abreviatura $\mathrm{PP}$, las fechas exaltadas por el régimen depuesto, las composiciones musicales "Marcha de los Muchachos Peronista" y "Evita Capitana" o "fragmentos de las mismas, y los discursos del presidente depuesto o su esposa o fragmentos de los mismos". Se prohíbe también la reproducción "mediante cualquier procedimiento, de las imágenes símbolos y demás, objetos 
señalados", mientras se declaran estas medidas como "de orden público y en consecuencia no podrá alegarse contra ellas la existencia de derechos adquiridos". El artículo 3 consigna, además, que quien "infrinja el presente decreto-ley será penado: con prisión de treinta días a seis años y multa de $\mathrm{m} \$ \mathrm{n}$ : 500 a $\mathrm{m} \$ \mathrm{n}$. 1.000.000; inhabilitación absoluta por doble tiempo del de la condena para desempeñarse como funcionario público o dirigente político o gremial" y cuando "la infracción sea imputable a una persona colectiva, la condena podrá llevar como pena accesoria la disolución". ${ }^{9}$

Se trata entonces de "borrar" -mediante ésta y otras resoluciones que disuelven la CGT, el IAPI y otros organismos gubernamentales- todo rastro del peronismo en la sociedad argentina y hacia allí dirige sus acciones el antiperonismo extremo, "los gorilas" (como desde 1955 llamaban los peronistas a la oposición) que ejercen las funciones de gobierno y ponen en vigencia la línea "Mayo-Caseros" para unir sus objetivos al pasado fundacional de la Nación, mientras derogan la Reforma Constitucional de 1949 y proyectan la Asamblea Constituyente para restablecer la Constitución Nacional de 1853. La propuesta se plasma en la Constitución de 1957 que deberá incluir, no obstante, gran parte de los derechos sociales obtenidos, mediante la incorporación del artículo 14 bis al texto de la ley fundamental de la Nación.

En este clima de confrontación, la educación es uno de los medios empleados para conseguir la "desperonización". Los niños ya no cuentan con sus libros de lectura del gobierno anterior -que son suprimidos e incautados en setiembre de 1955- y cuando al año siguiente retomen sus actividades escolares los cambios en los contenidos que reciban resultarán centrales. También habrá continuidades inalterables: los símbolos patrios, los hechos constitutivos de la Nación Argentina y las acciones de sus "próceres", las tradiciones y costumbres del país, los roles según el género, la familia y la escuela como instituciones formativas básicas, así como los valores encarnados en la educación y el trabajo como mecanismos para el ascenso social, que seguirán vigentes (Wainerman y Barck de Raijman, 1987). Es esta trama cultural y educativa la que brinda una red de contención y sentido de pertenencia a la sociedad argentina para mantener sus principios y valores colectivos, cuando las instituciones democráticas y los principios republicanos son cuestionados, vulnerados y sometidos desde el poder (Puiggrós, 1996).

Para comprender el impacto de los cambios es importante recurrir a los estudios de caso, dos de ellos al menos, de los muchos que podrían seleccionarse y que refieren a los libros de lectura utilizados en la escuela pública durante los

${ }^{9}$ [en línea] https://www.boletinoficial.gob.ar/detalleAviso/primera/7030451/19560309 
primeros años del ciclo de la escolaridad primaria. Se trata de libros que mediante lecturas sencillas combinan valores, principios, recreación y conocimientos, como parte del aprendizaje. El primero de los textos seleccionados es El Alma Tutelar, editado una vez producida la muerte de Eva Perón y destinado a niños de 7 años de edad (primer grado superior). El segundo, es Ruta Gloriosa, editado en 1957, cuando el antiperonismo se consolida, está destinado a niños de 10 años que cursan el cuarto grado del ciclo primario. Orientan esta elección dos cuestiones centrales: 1. los temas, el lenguaje y las características de las lecturas en tiempos del peronismo y del antiperonismo hacia mediados del siglo XX; y 2. la edad de los niños que por entonces transitarán del primer grado superior, cuando leen textos breves, en tiempos del peronismo al cuarto grado cuando reinician su curso completo, con lecturas más extensas, en tiempos del antiperonismo. El propósito es conocer las características que asume en cada tramo del trayecto educativo ese tránsito orientado desde el poder político, en la formación de estos niños escolarizados, para poder compararlos e interpretar cambios y continuidades, como parte de decisiones gubernamentales más o menos explícitas, pero en todos los casos dispuestos a consolidar la identidad nacional y los valores ciudadanos con perspectiva política.

\section{La "Nueva Argentina” a través de la lectura de El Alma Tutelar}

Son numerosos los libros de lectura distribuidos y recomendados por el peronismo para la enseñanza en el nivel primario de las escuelas públicas, acerca de los cuales la historiografía argentina ha dedicado estudios específicos (Corbière, 1999). Del conjunto, la selección hecha para este estudio de caso recae en el texto de Blanca Alicia Casas, titulado El Alma Tutelar, editado por Luis Lasserre, en Buenos Aires, en 1954, a dos años de la muerte de "Evita". Su tapa dura muestra las imágenes coloridas de una niña y un niño felices, mirando al cielo y en la contratapa interior un dibujo de los niños caminando desde su casa humilde a la escuela mientras atraviesan un campo con vacas y ovejas. Conforme a las disposiciones oficiales se incluyen lecturas que expresan "los objetivos del Segundo Plan Quinquenal". En un todo de acuerdo con "la vuelta al campo", el libro de lectura recoge los logros del gobierno peronista, incluyendo un compendio de las riquezas nacionales (Casas, 1954: 45). Desde la primera lectura, con el amparo de la bandera argentina, se recuerda al alumno la transformación de "una nación socialmente justa; económicamente libre y políticamente soberana" (Casas, 1954: 1). La tarea escolar está tutelada por "los retratos del señor Presidente de la República y su esposa; bajo cuyas miradas protectoras trabajamos tranquilos, seguros de su asistencia permanente", sin olvidar que la escuela "es un lindo regalo que me ha hecho Dios" 
(Casas, 1954: 2), consignan las lecturas del libro. La doctrina justicialista y la doctrina social de la iglesia se legitiman mutuamente.

Los vínculos y similitudes entre la madre de familia y Eva Perón, así como los del padre con los del Presidente Juan Perón, forman parte de lecturas consecutivas. "Mamá es el ángel tutelar de la casa" (Casas, 1954: 7) y Eva "es el alma tutelar de los niños" (Casas, 1954: 8-9). Por su parte, "papá es fuerte. Trabaja todo el día, y cuando regresa, conversa con mamá o juega con nosotros" (Casas, 1954: 10). No se deja de advertir que "lo que papá es para nosotros, el Presidente Juan Perón es para todos los hombres de este suelo argentino" (Casas, 1954: 11). La familia, los hermanos, los abuelos, las acciones realizadas por la Fundación de Ayuda Social "María Eva Duarte de Perón", la salud pública, la economía, integran un $40 \%$ de las lecturas de este texto escolar. La conducta, el ahorro, el respeto, ser "un buen niño" que "todo lo hace bien" y que "por sus virtudes puede llegar a ser Presidente de la República" (Casas, 1954: 20) son recomendaciones y actores característicos de la Argentina que aunque se empeña por desarticular el país embudo destaca la importancia del puerto de Buenos Aires y la riqueza que genera el "granero del mundo" (Casas, 1954: 21, 45, 55, 59, 83), sin olvidar "los derechos del trabajador" (Casas, 1954: 38, 53 y 72) .

\section{Imagen 2}

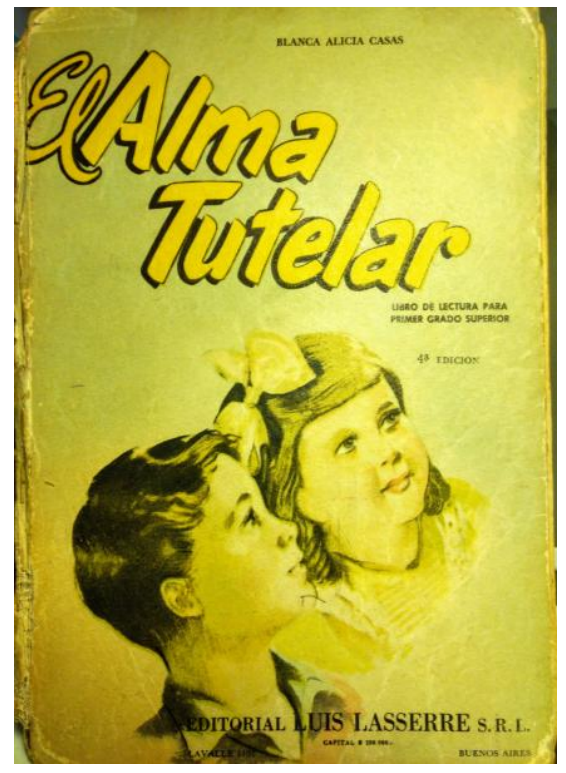

Casas, B. A. (1954). El Alma Tutelar.

Libro de lectura para primer grado superior. Editorial Luis Lasserre. 
En cumplimiento con lo establecido por las normas vigentes, los libros escolares incluyen desde 1953, lecturas que expresan los objetivos del Segundo Plan Quinquenal:

"Perón quiere que el campo produzca mucho y que su población humana sea feliz [...] Las asociaciones de campesinos o cooperativas le facilitarán la maquinaria para poder producir más con menos trabajo. El gobierno fijará los precios más altos a los productos del campo [...] En todas las escuelas se difundirá la benéfica acción del campo. Muchos niños y jóvenes, se dedicarán a las tareas agropecuarias" (Casas, 1954: 45).

Se trata de asuntos que son abordados en un $30 \%$ de las lecturas.

Por su parte, los acontecimientos y símbolos patrios asociados a las fechas históricas destacadas por el peronismo (17 de octubre de 1945, independencia económica de 1947, nacionalización de los servicios públicos) completan estas lecturas para niños de 7 años que cursan sus estudios en la escuela pública de la “Nueva Argentina" (Casas, 1954: 15). Así, por ejemplo, el escudo nacional de 1813 se asocia a la revolución del 4 de junio de 1943 (Casas, 1954: 33) y al escudo peronista; mientras la independencia del 9 de julio de 1816 se vincula a la firma de la independencia económica que concreta el Presidente Juan Perón en la histórica Casa de Tucumán el 9 de julio de 1947 (Casas, 1954: 49-50). Los constructores del pasado fundacional de la Nación, más allá de las afinidades políticas, no son ignorados por el peronismo y, en un "diálogo con Sarmiento", el ex presidente de origen sanjuanino y promotor de la educación del siglo XIX, es presentado como un hombre nacido en un hogar pobre pero laborioso y pacífico que lo convertirían en "un obrero incansable" (Casas, 1954: 73-74).

El Alma Tutelar se despide en su última lectura con un "SSalud, Argentina!", en términos similares a los del comienzo del texto y no ajenos a la doctrina justicialista. El alumno honra a la Patria en tanto "soldado", como San Martín, Belgrano, Moreno, agregando dos nombres a la Historia Argentina: “Trabajo, abnegación y sacrificio en el de Eva Perón. Patriotismo y firmeza en el de Juan Perón. Para ella el recuerdo imperecedero; para él la lealtad absoluta" (Casas, 1954: 92-93). El mensaje es explícito y alcanza a todos los niños escolarizados de la Nación Argentina, prescindiendo de la filiación política de los miembros de los hogares a los cuales pertenecen. 


\section{El modelo propuesto por Ruta Gloriosa}

Una vez producidos los hechos de la llamada "Revolución Libertadora" del 16 de setiembre de 1955 que interrumpen una vez más el ejercicio de la democracia, otros son los mensajes que reciben los mismos niños - en otro grado del ciclo educativoen la escuela pública argentina a través de sus libros de lectura, cuya autoría responde ahora a intelectuales y académicos reconocidos como el filósofo, historiador y ensayista Arturo Capdevilla y el escritor Julián García Velloso. Es el caso del libro de lectura Ruta Gloriosa, para cuarto grado del ciclo escolar primario, aprobado por el Consejo Nacional de Educación (Expte. 6503/57) y editado en 1957 por la Editorial Kapelusz, en cuya tapa el cruce de los Andes realizado por el Libertador General José de San Martín marca desde la imagen colorida y marcial, el rumbo de la identidad nacional. Este es el segundo libro de lectura elegido para ser analizado con el enfoque microhistórico propuesto.

El pasado fundacional de la Nación Argentina, sus gestas y símbolos patrios, sus paisajes y riquezas naturales, sus costumbres más tradicionales, el desconocimiento del pasado indígena, el perfil hispanista de su historia, dan consistencia a un mensaje cultural sólo en apariencia más equitativo y nutren con él las páginas de este libro de lectura, que también hará un uso político del pasado para pronunciarse contra el accionar del gobierno peronista con un estilo elíptico, pero sin dejar lugar para el disenso y la pluralidad de ideas (Artieda, 2017). El 60\% de las lecturas están dedicadas, en este caso, a las diversas provincias que componen el país, sus economías regionales, sus tradiciones y sus pobladores asociados al trabajo rural no sólo en la región pampeana, sino también en Mendoza y sus viñedos; Misiones, el cultivo del té y sus yerbales; Corrientes, su ganado y sus cítricos; Chubut y su petróleo; Santa Cruz, Tierra del Fuego y su actividad pesquera; Tucumán y la caña de azúcar; Chaco y el "oro blanco" (algodón). Ruta Gloriosa reivindica el libro como un recorrido inteligente para alcanzar un "saber digno", el que brindan "los hombres y los sabios de la nacionalidad", inspirándose en "el amor a la patria, en el culto a sus nobles héroes, en el anhelo de seguir el camino que nos trazaron" (Capdevila y García Velloso, 1957: 1), señalan sus páginas, sin diferir en este aspecto y en sus raíces, del mensaje educativo de los tiempos del peronismo. 


\section{Imagen 3}

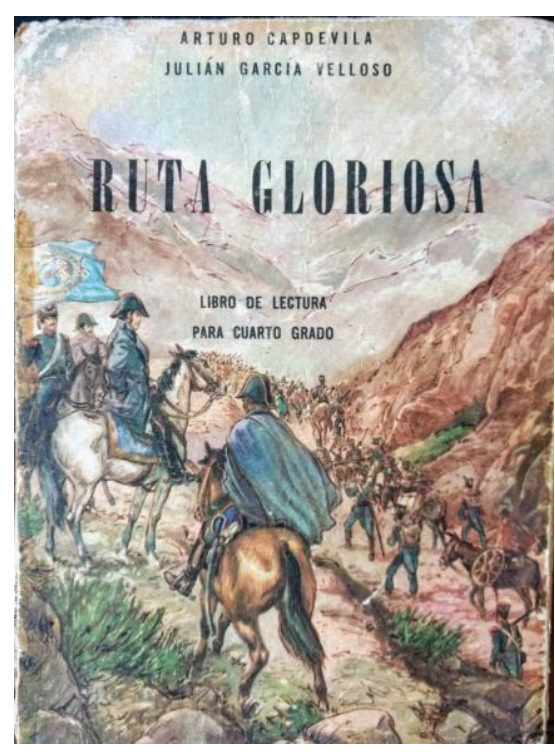

Capdevila, A. y García Belloso, J. (1957). Ruta Gloriosa.

Libro de lectura para cuarto grado. Editorial Kapelusz.

Es en la segunda lectura de este texto -acompañado por imágenes coloridas- la que refiere a "la Patria antes de la Revolución de Mayo", cuando las diferencias se hacen manifiestas. Retorna al escenario histórico la "Madre Patria", España, como sinónimo de civilización, una continuidad "de lo que era en el continente europeo"; mientras la gesta de Mayo de 1810 se identifica con una situación idílica y no de confrontación, "como cuando un hijo llega a la mayoría de edad y se aleja de la casa de sus padres para formar su propio hogar" (Capdevila y García Velloso, 1957: 2-3). La histórica relación con Inglaterra también cobra entonces otra dimensión en una de las lecturas dedicada a "la muerte de Mariano Moreno", cuando en un diálogo del poeta Carlos Guido y Spano con su hijo, aquél le recuerda que el cuerpo muerto del hombre de Mayo, al ser arrojado al mar, no sería envuelto por la bandera argentina que no estaba creada, sino por "una bandera inglesa", subrayando que "nos une ese amistoso lazo con Inglaterra desde que nacimos a la historia" (Capdevila y García Velloso, 1957: 84). Más allá de estas interpretaciones, se destaca la importancia por legitimar el accionar del gobierno de facto en los hechos fundacionales de la Nación, cuando se presenta unas páginas más adelante, la caracterización simbólica de la Pirámide situada en la Plaza de Mayo de la Capital Federal, calificándola como "Conmemorativa de la Revolución Libertadora de Mayo y de su basamento que venía a ser propiamente el altar de la Patria" (Capdevila y García Velloso, 1957: 41). 
Además de los hombres que gestaron la Nación Argentina y que siempre estuvieron presentes en los contenidos de la educación primaria, como el General José de San Martin y su epopeya de los Andes, Manuel Belgrano y su participación en las guerras por la independencia y la creación de la bandera nacional, Mariano Moreno y la "Representación de los Hacendados", retornan a las páginas de estos libros "el vencedor de Caseros" y Presidente de la Confederación Argentina, General Justo José de Urquiza (Capdevila y García Velloso, 1957: 16-17; 38-39), Bernardino Rivadavia como estadista (Capdevila y García Velloso, 1957: 160-161) "constructor y organizador de la Patria" (Capdevila y García Velloso, 1957: 163), el Obispo Fray Mamerto Esquiú y su accionar eclesiástico en Córdoba (Capdevila y García Velloso, 1957: 32-33), Fray Justo Santa María de Oro y su desempeño en la gesta independentista de 1816 (Capdevila y García Velloso, 1957: 54-56), el General Julio A. Roca y su liderazgo en "la conquista del desierto" como "centinela eterno de la nacionalidad" (Capdevila y García Velloso, 1957: 58-59).

Pero sin dudas es una de las últimas lecturas de este texto titulada "Dolores y Chascomús" (Capdevila y García Velloso, 1957: 167-168) la que muestra con nitidez el uso político y ejemplificador del pasado para justificar los hechos que lleva adelante la "Revolución Libertadora" con el propósito de "desperonizar" a la sociedad argentina. En este caso alude a los levantamientos en 1839 de esos pueblos bonaerenses (Dolores y Chascomús) "contra la tiranía de Rosas" (¿de Juan Perón?). Pobladores en armas a los que la lectura califica como "compañeros" -un término propio de los afiliados al peronismo- que "se arrancaban de la solapa la divisa federal" (¿el escudo peronista?, ¿el luto por la muerte de Eva Perón?), mientras "destrozaban el retrato (de Rosas) y con él, varios bustos de yeso que representaban al Restaurador" (¿los símbolos que el decreto 4161/56 ordenara destruir?). Este es el mensaje que reciben los niños argentinos a mediados de la década de 1950, quienes con anterioridad poco o nada habían leído acerca de tiranías y restauradores.

Respecto de la vida cotidiana, si en los tiempos del peronismo los barrios populares del conurbano bonaerense y las casas obreras ocupan un lugar central en los libros de lectura, desde 1956 la Capital Federal y sus barrios más distinguidos como Palermo, Recoleta, el Jardín Botánico, las barrancas de Belgrano toman ese lugar (Capdevila y García Velloso, 1957: 88-89). Un escenario que acompañan los sectores sociales pertenecientes a la clase alta o media alta, como se advierte en "yo quiero ser maestra", la última lectura de este libro, donde la protagonista es la amiga mayor de una niña, que se dedica a la escultura que modela "el busto de la gran maestra Rosario Vera Peñaloza que proyecta para ser colocado como un homenaje a su hermosa labor civilizadora, en la rosaleda de Palermo" (Capdevila y García Velloso, 1957: 176). Las diferencias con los tiempos 
del peronismo se explicitan cuando el obrero y su familia no son motivo de algunas de estas lecturas; pero también se destacan las permanencias respecto de la responsabilidad y los compromisos con la educación y el esfuerzo en la que todo escolar debe ser formado, cuando el padre le dice a su pequeña hija -en esa misma lectura- que si desea ser maestra "lo seas como lo fue Rosario Vera Peñaloza, y que con el correr del tiempo, también se coloque un busto tuyo en algún jardín o parque de la ciudad y lleve tu nombre alguna escuela" (Capdevila y García Velloso, 1957: 176).

La conducta ejemplificadora, la identidad nacional y los valores se siguen enseñando a través de ejemplos paradigmáticos como lo son las Máximas que el General José de San Martín redactara para su hija Merceditas con el objetivo de humanizar su carácter, su sensibilidad, el respeto a la verdad, la caridad, la indulgencia religiosa, la formalidad, los modales, el amor a la patria y la libertad (Capdevila y García Velloso, 1957: 100-102). Mientras el valor de la educación, la afición por la lectura y el esfuerzo para lograr los objetivos de vida se aprenden a través de fragmentos de Recuerdos de Provincia, escrito por el sanjuanino Domingo Faustino Sarmiento (Capdevila y García Velloso, 1957: 114-115), aunque ya no sea como en tiempos del gobierno peronista "un obrero incansable". Por su parte, el ejercicio ciudadano para las mujeres que en la Argentina se obtiene durante la gestión liderada por Juan Perón (1947), este libro de lectura lo ignora; le arrebata el logro al gobierno precedente y lo generaliza como una concesión que se da "en todas las naciones" (Capdevila y García Velloso, 1957: 129-130). En materia de roles femeninos, las estrategias se mantienen y las niñas que serán mujeres del mañana, tienen sus desempeños principales asociados a la familia, la maternidad y el cuidado y las tareas del hogar, como quedara plasmado en La Razón de mi Vida atribuida a Eva Perón, en la publicidad y en los libros de lectura de gran parte del siglo XX.

\section{Reflexiones finales}

La red cultural sostenida por el trabajo, la educación, el respeto por el otro, la solidaridad y la responsabilidad a través de la conducta, permite superar a la Nación Argentina los virajes políticos y los quiebres institucionales que pusieran en jaque varias veces a la democracia y a la república. El derrocamiento del Presidente Juan Perón es el punto de partida de un proceso de inestabilidad política creciente en la Argentina, que se enlazaría a la violencia de los años 70 . El conflicto político entre peronismo-antiperonismo a partir de la segunda mitad de los años '50, no tardaría en producir el desgranamiento de la compleja y heterogénea coalición antiperonista triunfante con la "Revolución Libertadora", 
cuando el empeño por destruir al oponente se convierta en el eje sustancial de su programa político basado casi exclusivamente en una confrontación que se desplaza entre la negociación y el conflicto (Spinelli, 2000: 189-220). En simultáneo, el peronismo proscripto comienza a pendular entre la resistencia y la anhelada participación política (James, 2006). El antiperonismo "como fenómeno político cultural" pondría el acento, según sus discursos, en la "restauración de los valores republicanos y culturales vulnerados por el peronismo" (Spinelli, 2000: 192), como parte de lo que el sociólogo Gino Germani llamaba la "paradoja argentina". Vale decir, cuando más allá de las diferencias políticas, la Argentina siga siendo retratada desde la ciudad puerto de Buenos Aires y con una visibilidad relativa de las diversidades y desigualdades regionales de su territorio y de sus pueblos originarios. Se reconoce a la Argentina rural y a sus principales agroindustrias regionales, pero se refuerza, una y otra vez, su imagen como país "granero del mundo".

Las reflexiones acerca de la construcción del discurso histórico y sobre el medio social en las que aquéllas se formulan, permiten comprender las diferentes "modalidades de la relación que las sociedades mantienen con el pasado" (Chartier, 2007: 34) que permiten diferenciar memoria e historia como oponentes en el reconocimiento del pretérito y la representación del mismo. La lectura como la educación contribuyen a forjar la identidad nacional y los valores que le dan envergadura a lo que entre fines del siglo XIX y gran parte del XX se denomina "la argentinidad". También los roles referidos al género se consolidan como parte de la escolaridad del ciclo primario, acompañando las características y principios sostenidos en la familia nuclear de entonces y en la escuela como institución de formación y contención. Los libros de lectura resultan un buen ejemplo para avanzar en estas cuestiones que se nutren de una composición de la sociedad argentina de perfil inmigratorio, pero también de migraciones internas desde los años de 1930. Todo inmigrante, y más tarde quienes migran del campo a la ciudad, construye su arraigo y el de sus hijos desde la educación y el trabajo, como factores de inclusión en una sociedad desigual, de la cual también dejan registros estos libros de lectura, cuyos contenidos se abordan en estas páginas a través de los estudios de caso elegidos. El contexto histórico es cambiante y no depone sus férreas oposiciones, mientras construye imágenes sobre "el otro" para dar consistencia al mundo de las representaciones sobre la realidad, con indudable connotación política.

En El Alma Tutelar el culto al líder y a su esposa, los hechos destacados de la conformación del partido peronista y sus logros, son características principales de muchas de las lecturas para los niños escolarizados. También la realidad cotidiana del obrero y los barrios populares, la salud pública, el ahorro, la familia y los roles 
que en ella cumplen el padre, la madre, los abuelos, los hermanos y el mismo niño, junto con los símbolos patrios, los hechos fundacionales de la Nación y los valores propios de la conducta y la responsabilidad derivados de la educación y el trabajo, son cuestiones que ocupan un espacio importante en el mensaje que transmiten las lecturas y que heredan del sistema educativo de las décadas anteriores. Cambios y continuidades, como parte de sus estrategias y estilo de gobierno, se combinan en la "Nueva Argentina" liderada por el Presidente Juan Perón.

Por su parte, en Ruta Gloriosa se emprende la reconstrucción del pasado con la mirada puesta en Europa, mientras desde sus páginas se transmite un esfuerzo por destacar las diversidades regionales de una Argentina de base agropecuaria y perfil agroexportador, pero capaz de atender a las necesidades de su mercado interno. Los símbolos patrios permanecen inalterables, como los hombres que construyeran la Nación Argentina, aunque aparezca una mayor presencia de los militares considerados "héroes de la patria" y una franca oposición al federalismo encarnado en los caudillos del siglo XIX. La Nación se presenta como heredera de los valores y la cultura europea, mientras los orígenes hispánicos vuelven al escenario educativo. La red que indica permanencias en la sociedad argentina pasa por la familia, los roles de género perfectamente determinados, los valores éticos y la importancia de la educación y el trabajo como símbolos del "progreso" y el ascenso social, aunque en sus lecturas no se advierta la presencia del obrero y los barrios populares como en los tiempos del peronismo.

Más allá de las diferencias notorias que muestra el análisis histórico realizado, ambos libros de lectura mantienen una sólida estructura cultural de valores que son propios de la identidad nacional, ciudadana, ética, cristiana, y jerárquica en materia de roles, funciones y responsabilidades, que caracterizan a la Argentina de mediados del siglo XX, más allá de los cambios gubernamentales y los quiebres institucionales. El uso político del pasado respalda cada uno de los mensajes que transmiten los libros de lectura y el niño que inicia su escolaridad primaria en tiempos del peronismo debe adaptarse a los contenidos e interpretaciones que implementa la "Revolución Libertadora". La escuela pública, la metodología de la enseñanza que se imparte, los valores, la importancia de la familia, el cuidado del medio ambiente son los asuntos que perduran, pero los niños tienen que aprender a lidiar con ausencias y nuevas presencias. Así lo registra el estudio pormenorizado de los casos analizados para destacar permanencias y modificaciones en la enseñanza inicial argentina sobre el mismo núcleo generacional de niños escolarizados.

La educación como parte sustantiva de la cultura que mediatiza la relación entre el Estado y la sociedad, se convierte así en un férreo sustento para reconocer las bases esenciales del pasado fundacional de la Nación, que los quiebres 
institucionales no logran destruir al menos hasta promediar el siglo XX (Tedesco, 2020: 351-371). En todo el decenio de 1950, las lecturas de estos textos escolares refieren a los mismos principios éticos, la centralidad de la familia, de la escuela, del trabajo $\mathrm{y}$, en esencia, de la educación pública, que permanecen como instrumentos de inclusión social y se imponen a los vaivenes políticos y al deterioro de la república y sus instituciones. Se trata de asuntos que forman en conjunto una trama que hace posible resguardar la coherencia, cohesión y fundamentos de identidad de la sociedad argentina, en medio de la inestabilidad política cada vez más frecuente en lo que resta del siglo XX. Pero también se sostiene la presencia del "país embudo", desigual y concentrado, que se organiza en torno a la ciudad puerto de Buenos Aires, su burocracia político administrativa y su poderosa presencia económico financiera, que los libros de lectura analizados -sin distinción temporal- registran sin ambigüedades en sus lecturas.

\section{Referencias bibliográficas}

Altamirano, C. (1999). Intelectuales y pueblo. En C. Altamirano (Ed.), La Argentina en el siglo XX. Ariel.

Álvarez Junco, J. (1994). El populismo como problema. En J. Álvarez Junco y R. González Leandri. El populismo en España y América (pp. 11-38). Editorial Catriel.

Artieda, T. L. (2017). La alteridad indígena en libros de lectura de Argentina (ca. 18851940). Consejo Superior de Investigaciones Científicas.

Ascolani, A. (2010). Libros de lectura en la escuela primaria argentina: civilizando al niño urbano y urbanizando al niño campesino (1900-1946). Educação em Revista 26 (1), 303-325. [en línea] https://doi.org/10.1590/S0102-46982010000100015

Ascolani, A. (2019). Reformismo pedagógico, utilitarismo y nacionalismo en las escuelas primarias de la Argentina durante la crisis de 1930. Revista Lusófona de Educaçao, (43), 149 -162.

Ascolani, A. (2020). Nacionalistas y libertarios: tensiones en torno de las conmemoraciones y símbolos patrios en la educación primaria (Argentina, 19101930). Revista Brasileira de Historia da Educacao, Maringá, (20), 1-23.

Bairoch, P. (1995)._Mythes et paradoxes de l'histoire économique. La Découverte.

Banco de la Nación Argentina (BNA) (1948). Memoria y balance del ejercicio de 1947. BNA.

Barbero, M. I. y Devoto, F. (1983). Los nacionalistas. Centro Editor de América Latina (CEAL). 
Belini, C. (2018). Una radiografía crítica de la economía peronista. El Colegio libre de Estudios Superiores y los cursos de economía argentina de 1940 y 1950. A Contra Corriente. Una revista de Estudios Latinoamericanos, 16 (1), 264-293.

Bottaro, R. (1964). La edición de libros en la Argentina. Troquel.

Braslavsky, B. (2005). Enseñar a entender lo que se lee. La alfabetización en la familia y en la escuela. Fondo de Cultura Económica.

Campbell, F. (1997). Los intelectuales y el poder. En L. Baca Olamendi e I. Cisneros (Comps.), Los intelectuales y los dilemas políticos en el siglo XX (pp. 27-32). FLACSO/Triana Editores, t. 1.

Capdevila, A. y García Belloso, J. (1957). Ruta Gloriosa. Libro de lectura para cuarto grado. Kapelusz.

Casas, B. A. (1954). El Alma Tutelar. Editorial Luis Lasserre.

Ciria, A. (1983). Política y cultura popular: La Argentina peronista (1946-1955). Ediciones de La Flor.

Corbière, E. J. (1999). Mamá me mima, Evita me ama. La educación argentina en la encrucijada. Sudamericana.

Cucuzza, H. R. (2007). Yo argentino. La construcción de la Nación en los libros escolares (1873-1930). Miño y Dávila.

Chartier, R. (2007). La historia o la lectura del tiempo. Gedisa.

De Ipola, E. (1999). El hecho peronista. En C. Altamirano (Ed.), La Argentina en el siglo XX (pp. 325-332). Ariel.

De La Torre, C. (1994). Los significados ambiguos de los populismos latinoamericanos. En J. Álvarez Junco y R. González Leandri El populismo en España y América (pp. 39-60). Editorial Catriel.

Filmus, D. (1996). Estado, sociedad y educación en la Argentina de fin de siglo. Troquel.

Foucault, M. (1985). Un diálogo sobre el poder. Alianza Editorial, 2da. Edición.

García, E. A. (1965). Desarrollo de la industria editorial argentina. Fundación Biblioteca Franklin.

Girbal-Blacha, N. (1997). Dichos y hechos del gobierno peronista (1946-1955). Lo fáctico y lo simbólico en el análisis histórico. Entrepasados, (13), 63-77.

Girbal-Blacha, N. (2012). La industria invisible. Entre las finanzas y la política. Empresas de cultura popular en la Argentina peronista (1946-1955). H-Industria Revista, (11), 110-134. 
Habermas, J. (1986). Perfiles filosófico-politicos. Taurus.

Habermas, J. (1973). Problemas de legitimación en el capitalismo tardío. Amorrortu Editores.

James, D. (2006). Resistencia e integración. El peronismo y la clase trabajadora argentina. Siglo XXI Editores.

Lechner, N. (1997). Intelectuales y política. En L. Baca Olamendi e I. Cisneros (Comps.). Los intelectuales y los dilemas políticos en el siglo XX (pp. 33-35). FLACSO/Triana Editores, t. 1.

Neiburg, F. (1998). Los intelectuales y la invención del peronismo. Alianza Editorial.

Partido Peronista. Consejo Superior Ejecutivo (1988). Manual del peronista. Ediciones Los Coihues (primera edición 1948)

Presidencia de la Nación Argentina (1955). El pueblo a través del pensamiento de Perón. Presidencia de la Nación-Secretaría de Prensa y Difusión.

Presidencia de la Nación. Subsecretaria de Informaciones (1953). Segundo Plan Quinquenal. PEN.

Prost, A. (1996). Histoire, vérites, méthodes. Des structures argumentatives de l"histoire. Le Débat, (92), Gallimard, 127-140.

Puiggrós, A. (1996). Dictaduras y utopías en la historia reciente de la educación argentina. Galerna.

Puiggrós, A. (2003). Qué pasó en la educación argentina: breve historia desde la conquista hasta el presente. Galerna.

Quattrocchi-Woisson, D. (1995). Los males de la memoria. Emecé Editores.

Rioux, J.-P. et Sirinelli, J.-F. (1997). Pour une histoire culturelle. Seuil.

Rivera, J. B. (1998). El escritor y la industria cultural. Atuel.

Sampay, A. (1975). Las Constituciones de la Argentina (1810-1972). Eudeba.

Sardi, V. (2009). El rol de la literatura en la escuela primaria argentina en el marco de la construcción de identidades nacionales (1900-1940). Tesis doctoral, UNLP. [en línea] http://www.memoria.fahce.unlp.edu.ar/tesis/te.459/te.459.pdf

Secretaría de Educación (1948). Decreto 8.954, Buenos Aires, 27 de marzo (folleto).

Sidicaro, R. (1995). Contribuciones para el estudio de las ideas políticas de Perón. En Estudios Sociales. Revista Universitaria Semestral, (9), 31-38.

Somoza Rodríguez, M. (2006). Educación y Política en Argentina (1946-1955). Miño y Dávila. 
Spinelli, M. E. (2000). La "Revolución Libertadora". Proyección política. Un análisis sobre su lugar en la historiografía. En M. E. Spinelli; A. Servetto y M. Ferrari. La conformación de las identidades políticas en la Argentina del siglo XX (pp. 189-220). UNC-UNICen-UNMdP.

Tedesco, J. C. (1980). La educación argentina 1930-1955. Centro Editor de América Latina.

Tedesco, J. C. (1986). Educación y sociedad en la Argentina (1880-1945). Ediciones Solar.

Tedesco, J. C. (2020). Educación y Sociedad en la Argentina (1880-1955) (pp. 351-371). UNIPE. Editorial Universitaria. Anexo.

Terán, O. (1985). Presentación y selección. Michel Foucault. El discurso del poder. Folios Ediciones.

Toro y Gómez, C. (1935). La Escuela y la Vida. Libro de lectura para 3er grado. Editorial Kapelusz.

Wainerman, C. H. y Barck de Raijman, R. (1987). Sexismo en los libros de lectura de la escuela primaria. Ediciones del IDES 13.

Zanatta, L. y Di Stefano, R. (2009). Historia de la Iglesia Argentina. Desde la Conquista hasta fines del Siglo XX. Sudamericana, tercera parte.

Zubieta, A. M. et al. (2000). Cultura popular y cultura de masas. Conceptos, recorridos y polémicas (pp. 37-41). Paidós. 